Western University

Scholarship@Western

Department of Economics Research Reports

Economics Working Papers Archive

1986

\title{
A Dynamic Model of Redistribution, Inheritance and Inequality
}

James B. Davies

Peter Kuhn

Follow this and additional works at: https://ir.lib.uwo.ca/economicsresrpt

Part of the Economics Commons

Citation of this paper:

Davies, James B., Peter Kuhn. "A Dynamic Model of Redistribution, Inheritance and Inequality." Department of Economics Research Reports, 8602. London, ON: Department of Economics, University of Western Ontario (1986). 
RESEARCH REPORT 8602

\section{A DYNAMIC MODEL OF REDISTRIBUTION,} INHERITANCE AND INEQUALITY
James B. Davies and
Peter Kuhn

Department of Economics

University of Western Ontario

London, Ontario, Canada.

February 1986

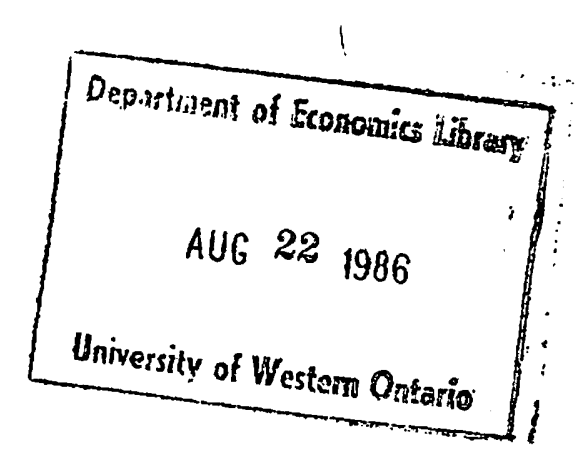


A DYNAMIC MODEL OF REDISTRIBUTION, INHERITANCE AND INEQUALITY

\author{
James B. Davies \\ and \\ Peter Kuhn
}

\author{
Department of Economics \\ University of Western Ontario \\ London Canada
}

February 1986 


\section{Introduction}

Due to the work of Stiglitz (1978), Laitner (1979a and b), Atkinson (1980), Ioannides and Sato (1982) and others it is now well known that inheritance may have an equalizing impact on the steady-state intragenerational distributions of income and consumption. This somewhat surprising result is derived in models with various forms of bequest behavior, but with the common element of fresh stochastic shocks in each generation. Bequests may equalize by dampening these shocks through the sharing of luck across the generations of a family.

Given the possible equalizing role of inheritance, is it necessarily inequality-reducing in the long run to tax inheritances, with the revenues (perhaps) funding transfer payments? Using a model with regression to the mean in earnings ability, and intergenerational saving in proportion to income, Stiglitz (1978) argued that an excessive rate of inheritance tax might well be disequalizing. A similar result was obtained by Becker and Tomes (1979) in a steady-state model with "compensatory bequests" inversely related to children's "endowed" earnings capacities. In both these cases, inequality can rise even in the absence of general-equilibrium effects of redistribution on factor prices. Davies (1986) examines why this rise occurs and examines the conditions which make it more or less likely.

Unfortunately, while much is now known about the steady-state effects described above, little is known about the dynamic behavior of inequality over time in such models. Yet since generations last a "long" time and adjustment can be slow, information about transition is clearly very important. For example, Becker and Tomes (1979) speculate that, while the immediate effect of redistribution is likely to be equalizing, "perhaps this conflict between 
initial and long-run effects helps explain why the large growth in redistribution during the last 50 years has had very modest effects on inequality" (p. 1178). This conjecture depends on the notion that a fairly rapid adjustment to a point near a new (higher inequality) steady state has occurred.

This paper characterizes the transition path of inequality that arises from an increase in redistribution by solving out a fully dynamic version of the Becker-Tomes (BT) model. ${ }^{1}$ We show that, following a permanent increase in lifetime wealth taxation, inequality always falls in the impact generation, even when the change is fully anticipated and bequests are reduced in response to it. Indeed, regardless of whether the new steady-state inequality lies above or below the old, we show that inequality must always "overshoot" its new steady state value, falling to a level below the new steady state before approaching it from below. According to calculations with an example, minimum inequality occurs between four and six generations after the tax increase is announced. This occurs, even though the level of the "equalizing" transfer payment begins to fall after the first period, because the initial reduction in inequality is "passed on" through inheritances to subsequent generations. Results for other tax schemes (except a pure tax on endowed ability) exhibit patterns similar to that for lifetime wealth tax. Also, in all these schemes, the length and depth of the initial decline in inequality tends to be larger with higher mean inheritances--as implied, e.g., when inheritance includes expenditures on children's upbringing and education. similar results are also obtained when the BT model is modified to incorporate alternative motivations for bequests, such as "strategic" bequests or different forms of 
altruism. Thus our results do not support the Becker-Tomes conjecture, and suggest that explanations for the small changes in apparent inequality over the last 50 years be sought elsewhere--for example by considering endogenous factor prices, or in a re-examination of the data itself.

Section II of the paper outlines the structure of the model. Section III analytically characterizes the dynamic behavior of the key variables in the model, including that of a simple, scale-independent measure of inequality--the coefficient of variation of income. Section IV computes examples of transition paths for what we consider realistic parameter values, Section $v$ briefly considers alternative motivations for bequests and Section VI summarizes our conclusions.

\section{Yodel Structure}

The basic model is very similar to that of Davies (1986). ${ }^{2}$ In the society examined there is no mating. Asexual reproduction generates a cross-section of dynasties, each consisting of a succession of unattached individuals. 3 Generations do not overlap. To simplify the presentation, throughout Sections II and III we shall think of bequests as involving purely physical capital and of lifetime earnings as exogenous. The extent to which this is legitimate, and the ways the model can be reinterpreted to include transfers intended to support human capital investment, are discussed in section IV.

In a world without government, the lifetime wealth, $L_{t}$, of a member of generation $t$, would be composed of earnings and inheritances, $E_{t}$ and $I_{t}$ respectively. This wealth would be exhausted in consumption, $c_{t}$, and bequest, $B_{t}$. A member of generation $t$ would inherit $I_{t}$ where $I_{t}=r B_{t-1}$ and $r$ is one plus the interest rate. 
Factor prices are assumed to be fixed. Thus, for example, the before-tax rate of return on bequests, $r-1$, is exogenous and constant. Initially earnings are also exogenous, and regress to the mean across generations according to:

$$
\text { (1) } E_{t}=(1-v) \bar{E}+v E_{t-1}+c_{t}
$$

where $c$ is i.i.d. with mean zero. The size distribution of $E_{t}$ is constant

over time and is assumed to have finite variance $V(E)$ and mean $\bar{E}$.

Introducing government, proportional taxes on $E_{t}$ and $I_{t}$ are levied at rates $a$ and $b$ respectively. With the government's budget balanced within $a$ generation, this yields the revenue required to pay each individual the uniform transfer, $G_{t}$ :

(2) $G_{t}=\overline{a E}_{t}+\bar{b}_{t}$

(where a bar denotes a mean value, as it will throughout). By varying a and b, as in Davies (1986), various redistributive schemes may be examined, based on alternatively taxation of ${ }^{4}$

$$
\begin{array}{ll}
\text { (i) "lifetime wealth", } E_{t}+I_{t} & : a=b \\
\text { (ii) "lifetime income", } E_{t}+\frac{r-1}{r} I_{t}: a=b\left(\frac{r}{r-1}\right)>b
\end{array}
$$

$$
\begin{array}{ll}
\text { (iii) earnings, } E_{t} & : a>0, b=0 \\
\text { (iv) inheritances, } I_{t} & : a=0, b>0 .
\end{array}
$$

Note that since earnings are invariant with respect to all taxes and transfers considered in the paper, their taxation is effectively "lump sum". In contrast taxes on inheritance turn out to have important effects on behaviour. 
Given the above possibilities, lifetime wealth after-tax, $L_{t}$, is:

(4) $L_{t}=(1-a) E_{t}+(1-b) I_{t}+G_{t}$.

Substituting (2). into (4) and taking expectations, note that:

(5) $\bar{L}_{t}=\bar{B}_{t}+\bar{I}_{t}$

Thus mean lifetime wealth after-tax, $\bar{L}_{t}$, equals the sum of the total per capita resources available to the economy, $\bar{E}_{t}$ and $\bar{I}_{t}$, as would be expected.

It is assumed that all parents have identical utility functions. As in Becker and Tomes (1979) and Davies (1986) these functions depend on parent's consumption and child's after-tax lifetime wealth:

(6) $U_{t}=U\left(C_{t}, L_{t+1}\right)$.

and are strictly quasi-concave and homothetic. Thus the kind of bequest behavior that occurs in our model will be both altruistic (in the sense that utility is derived directly from some aspect of the child's consumption or income) and compensatory (in the sense that the parent adjusts his bequest behavior in response to changes in the child's endowment). "With "endowed" after-tax wealth, $\underline{L}_{t}$, given by $\underline{L}_{t}=(1-a) E_{t}+G_{t},(7)$ is maximized subject to:



where $\tilde{r}=r(1-b)$, and $z_{t}$ represents "family wealth".

Given the identical homothetic preferences and common interest rate, all parents consume a fraction, $(1-\theta)$, of family wealth: 
(8) $c_{t}=(1-\theta) z_{t}$

Substituting (8) into (7), we see that this leaves for the child:

(9) $L_{t+1}=\delta Z_{t}$.

where $\delta=\tilde{r} \theta$.

Under homotheticity, it is easy to show that $\frac{\partial \delta}{\partial a}=0$ and $\frac{\partial \delta}{\partial b}<0, i . e$.

$\delta$ is independent of the earnings tax rate and increases with the inheritance tax rate. From (8) and (9) it is also possible to sign $\frac{\partial \theta}{\partial \tilde{r}}$. Let the

elasticity of substitution between $C_{t}$ and $L_{t+1}$ be $\sigma$. Then we have:

(10) $\frac{\partial \theta}{\partial \tilde{r}} \stackrel{\geqq}{<} 0$ as $0<10^{3}$

Using equations (2), (7), and (9), it is straightforward to characterize the evolution of wealth for an individual dynasty in the model as a simple, linear first-order stochastic difference equation:

(11) $L_{t+1}=\delta L_{t}+\theta \underline{L}_{t+1}$

or

(12) $L_{t+1}=\delta L_{t}+\theta\left[(1-a) E_{t+1}+a_{t+1}^{-}+\overline{b I}_{t+1}^{-}\right]$.

Equations (11) and (12) provide the basis for all the dynamic analyses in Section III. 


\section{MODEI SOLUTIO:I}

This section characterizes the dynamic behavior of the main variables in the model in three stages. First, we examine the evolution of mean wealth, $\bar{L}_{t}$, which also suffices to characterize $G_{t}$. Second, we examine the path of the variance of lifetime wealth, and finally that of its coefficient of variation. In each case, we consider an economy in steady state for all $t \leq-1$. At $t=-1$, a new tax regime, which is to be effective for all $t \geq 0$, is announced. The tax changes we consider are separate increases in a and $b$, as well as combinations of the two that correspond to increases in lifetime income and wealth taxes.

1. Bvolution of $\bar{L}_{t}$ and $G_{t}$

The basic difference equation for mean wealth, $\bar{L}_{t}$, can be derived simply by taking means in (12) and rearranging:

(13) $\bar{L}_{t+1}=\frac{\delta}{1-b \theta} \bar{L}_{t}+\frac{\delta}{r(1-b \theta)} \bar{E}$

Equation (13) is stable if and only if $\delta /(1-b \theta)<1$, which we shall assume for the remainder of the paper. Equation (13) is also independent of the tax rate on earnings, a, so that mean wealth in any period is unaffected by the level of $a$ in any period. Thus we consider only the effect of $b$ on

$\overline{\mathrm{L}}_{\mathrm{t}}$ in what follows.

Solving (13) for steady-state mean wealth, $\tilde{L}^{-}$, yields: 
(14) $\bar{L}^{-}=\frac{(1-b) \theta}{1-b \theta-\delta} \bar{E}=\frac{\bar{E}}{1-r+r \frac{(1-\theta)}{\delta}}$

Under homotheticity, $\frac{1-\theta}{\delta}=\frac{c_{t}}{L_{t+1}}$ must increase with $b$, so that, as noted

by Becker and Tomes (1979, pp. 1176-77), steady-state mean income always declines as a result of redistributing inheritances in this model.

The evolution of $L^{-\star}$ from an old steady state at $t=-1$ to its new steady state is most easily described by solving (13). The general solution to (13) is:

(i5) $\bar{L}_{t}=k\left(\frac{\delta}{1-b \theta}\right)+\bar{L}^{-*}$

where $K$ is an arbitrary constant and $\bar{L}^{-*}$ is the new steady-state value of $\bar{L}$.

Finally, solving for $K$ such that the old steady-state, $\underline{\underline{L}}$, obtains at $t=-1$, (16) $\bar{L}_{t}=\left(\underline{L}^{-*}-\bar{L}^{-*}\right)\left(\frac{\delta}{1-b \theta}\right)+\bar{L}^{-*}$.

Thus, an increase in the tax rate $b$ causes mean wealth to decline monotonically, beginning at $t=0$. The rate of decline slows with time; or, more precisely, the difference between the old and new steady states is eroded at a geometrically declining rate, equal to $\left(\frac{\delta}{1-b \theta}\right)$. This of course implies a relatively large decline in mean wealth in the initial, or "impact" period, $t=0$, the size of which can be found by setting $t=0$ in (16): 
(17) $\bar{L}_{0}=\frac{\delta(1-\underline{b \theta})}{\underline{\delta(1-b \theta)}} \underline{-}$.

where lower bars denote old steady-state values.

The behavior of the transfer, $G_{t}$, is easily derived from that of

$\bar{L}_{t}$, by noting from (2) and (5) that:

(18) $G_{t}=(a-b) \bar{E}_{t}+\overline{b L}_{t}$.

Comparing steady states, it is clear that higher earnings taxes raise the steady state transfer (since $\bar{L}_{t}$ is unchanged when a rises), but that the effect of $b$ on the steady-state transfer is ambiguous: if the decline

in $L^{-*}$ that results from a higher inheritance tax is large enough, the steady-state transfer, $G^{*}$, may fall. Considering the time path of $G_{t}$ after a tax increase, it is clear that an increase in a alone at $t=0$ raises the transfer immediately to a level that remains constant thereafter. A tax increase in which $b$ alone increases, or both $a$ and $b$ rise (such as an increase in income or wealth taxes) causes a "jump" in the transfer at $t=0$, which may be positive or negative, followed by a smooth decline in $G_{t}$ (since $\bar{L}_{t}$ falls and $a$ and $b$ remain at their new levels). The size of the initial "jump" in $G_{t}$ is given (from (17) and (18)) by:

(19) $G_{0}=\left[a-\underline{a} \frac{b}{\underline{b}}\right] \bar{E}+\frac{b \delta(1-\underline{b \theta})}{\underline{b \delta(1-b \theta)}} \underline{G}$

When $a=b$ and $\underline{a}=\underline{b},(19)$ becomes

(191) $G_{0}=\frac{b \theta(1-\underline{b \theta})}{\underline{b \theta}(1-b \theta)} G$ 
Thus, under lifetime wealth taxation a necessary and sufficient condition for $G$ to rise in the impact generation is that bo increases with the tax rate, $b$. This amounts simply to being before the peak of the "Laffer curve" in the short run.

\section{Evolution of Variance ( $V$ )}

The basic difference equation for the variance of wealth can be derived by taking the variance of both sides of (12):

(20) $v_{t+1}=\delta^{2} v_{t}+\theta^{2}(1-a)^{2} v(E)+2 \delta \theta(1-a) \operatorname{Cov}\left(L_{t} \cdot E_{t+1}\right)$

The last term in (20) depends on the entire history of $\delta$ and $r$ and is, in general, time-dependent. For our purposes, we need only to characterize its behavior under two scenarios: first, one where $\delta$ and $r$ have been constant for all $t$, and second, one in which a preannounced (at $t=-1$ ) tax change occurs at $t=0$.

For the first, steady-state case, repeated substitution in (11) yields:

(21) $c^{*}=\operatorname{Cov}^{*}\left(E_{t+1}, L_{t}\right)=\frac{(1-a)}{(1-b)} \frac{v \delta}{r(1-v \delta)} v(E)$

which is decreasing in $a$, increasing in $\delta$, and (hence) decreasing in $b$.

The second case yields:

$$
\operatorname{Cov}\left(E_{t+1}, L_{t}\right) \mid \begin{aligned}
& \text { policy change } \\
& \text { at } t=0
\end{aligned}=c^{*}+\left(\underline{c}-c^{*}\right)(v \delta)^{t+1}
$$

where $\underline{c}^{*}$ is the old steady-state covariance.

Substituting (22) into (20) yields:

(23) $v_{t+1}=\delta^{2} v_{t}+A(v \delta)^{t+1}+B$

where $A$ and $B$ are both constants, with $A=2 \delta \theta(1-a)\left(\underline{C}^{*}-C^{*}\right)$ and 
$B=\theta^{2}(1-a)^{2} v(B)+2 \delta \theta(1-a) C^{\star}$. Equation (23) can be solved for steady-state variance of wealth to yield:

$$
v^{*}=\frac{B}{1-\delta^{2}}=\frac{\theta^{2}(1-a)^{2}}{1-\delta}\left\{\frac{1+v \delta}{1-v \delta}\right\} v(B)
$$

which is always decreasing in a (since $v \delta<1$ ) and always decreasing in $b$ if a=b (wealth taxation). As noted by Becker and Tomes (1979), however, this does not necessarily reveal the effects of $a$ and $b$ on relative inequality, if a scale-independent measure of inequality such as the coefficient of variation is used, since mean wealth is also affected by taxation here.

The general solution to (23) is:

$$
\text { (25) } v_{t+1}=\left[\frac{A v \delta}{\delta(v-\delta)}\right](v \delta)^{t+1}+\frac{B}{1-\delta^{2}}+K\left(\delta^{2}\right)^{t+1}
$$

while solving for $\mathrm{K}$ such that the system is in the old steady-state equilibrium at $t=-1$ yields:

$$
v_{t}=\operatorname{A\delta } \delta^{t}\left[\frac{v^{t+1}-\delta^{t+1}}{v-\delta}\right]+v^{*}+\left(\underline{v}^{*}-v^{*}\right)\left(\delta^{2}\right)^{t+1}
$$

where $\underline{v}^{\star}$ is the old steady-state variance.

Finally, substituting in A to express all quantities in (17) as functions of $v$ and $\delta$ only:

$$
v_{t}=v^{\star}+\delta^{t}\left[\underline{v}^{*}\left[\delta^{t+2}+\delta^{2}\left(\frac{1}{\delta^{2}}-1\right) \frac{\phi}{\Phi} D_{t}\right]\right.
$$

$$
\left.-v^{*}\left[\delta^{t+2}+\left(1-\delta^{2}\right) D_{t}\right]\right\}+\frac{\delta^{t+2} \phi(\phi-\phi) v(B) D_{t}}{r^{2}}
$$


where $D_{t}=\frac{v^{t+1}-\delta^{t+1}}{v-\delta}>0$ and $\phi=\frac{1-a}{1-b}$.

From (23), (24) and (27), the following can be concluded about the dynamic behavior of $v_{t}$ after a tax increase at $t=0$. First, regardless of the nature of the tax change, $v_{t}$ declines monotonically from its level in the impact generation, $v_{0}$, to the new steady state level, $v^{*}$, if and only if $v_{0}>v^{*} \cdot 8$ second, the behavior of $v_{t}$ in the impact generation is given by substituting $t=0$ in (27) yielding:

$$
v_{0}=\underline{v}^{*}\left[\delta^{2}\left(1-\frac{\Phi}{\Phi}\right)+\frac{\delta^{2} \phi}{\delta^{2} \Phi}\right]+\frac{\delta^{2}}{r^{2}} \phi(\phi-\phi) v(E)
$$

Inspection of (27) and (28) reveals the following about the effects of various tax increases:

If only the earnings tax, $a$, increases, then we have $\phi<\phi$, and $v_{0}<$ $\underline{v}^{*}$, from (28) (since the coefficient on $\underline{v}^{\star}$ is less than 1 and the constant term is negative). One can also show, using (28), that $v_{0}>v^{*} \cdot 9$ Thus, the variance of wealth declines monotonically from its old to its new steady-state value, although unlike $\bar{L} t$, the difference between the two values is not eroded at a geometrically declining rate.

If only the inheritance tax, $b$, increases, we have $\phi>\Phi$, and equation (28) no longer guarantees $v_{0}<\underline{v}^{*}$. Thus the variance of wealth may increase in the impact generation, when the inheritance tax rate alone is increased. However even if it does so, variance still declines monotonically to the new steady-state value after its initial upward jump. 
Considering an increase in a lifetime wealth tax ( $a=b$ before and after the tax increase; thus $\phi=\Phi)$, we note that (28) now simplifies to:

(28') $v_{0}=\frac{\delta^{2}}{\delta^{2}} \underline{v}$

Thus, the variance of wealth declines in the impact generation by an amount proportional to the fall in $\delta^{2}$. That $v_{0}$ is still above the new steady-state variance can be ascertained by finding:

$$
\frac{v}{v^{*}}=\frac{\left(1-\delta^{2}\right)}{\left(1-\underline{\delta}^{2}\right)} \frac{(1+v \underline{\delta})}{(1+v \delta)} \frac{(1-v \delta)}{(1-v \underline{\delta})}>1
$$

Thus, in the $a=b$ case, variance of wealth declines monotonically from $\underline{v}^{\star}$ to $v^{*}$. Examination of (27) also reveals that, comparing this case to one with the same initial conditions in which $b$ alone rises, $v_{t}$ is everywhere below what it would be if only the inheritance tax rate is increased.

Finally, consider a lifetime income tax increase. If we refer again to (27) we see that $\phi / \Phi$ and $\phi-\Phi$ play an important role in the transition equation for $v_{t}$. Interestingly, although $a$ and $b$ are in constant ratio under $a$ lifetime wealth tax, the ratio $\phi=\frac{1-a}{1-b}$ declines as the tax increases.

Referring to (27) this implies that for given $\underline{v}^{*}$ and $v^{*}$, the transition path is bounded above by the $\phi=\Phi$ path studied above in the lifetime wealth tax case. Otherwise, few additional analytical results appear to exist. 


\section{Bvolution of the coefficient of variation $\left(C v_{t}\right)$}

The behaviour of the coefficient of variation of wealth ${ }^{10}$ after a tax change depends on whether mean wealth declines more or less rapidly than the standard deviation of wealth. In this section we attempt to delineate conditions and time periods under which each of these occurs.

The steady-state coefficient of variation is easily derived from (13) and (24):

(30) $\mathrm{CV}^{*}=\phi \frac{1-\mathrm{b} \theta-\delta}{\sqrt{1-\delta}} \cdot \sqrt{\frac{1+v \delta}{1-v \delta} \mathrm{CV}(\mathrm{B})}$

which must decrease with $a$, but may increase or decrease with $b$. As shown in Davies (1986), with $a=b=0,(30)$ implies we must have $\mathrm{Cv}^{\star}<\mathrm{CV}(\mathrm{B}) .{ }^{11}$ Thus, since the CV of lifetime wealth would equal $\mathrm{CV}(B)$ if inheritance were outlined, intergenerational transfers are equalizing in this model.

The transitional path of $\mathrm{CV}_{\mathrm{t}}$ is simple when only a changes, but complex if $b$ also changes. As we saw above $\bar{L}_{t}$ is unaffected by $a$, while an increase in a will generate a monotonic decline in $v_{t}$. Thus an increase in a will lead to a steadily declining $\mathrm{CV}_{t}$ which asymptotes to a new, lower level of inequality.

Some intuition regarding the transitional path of $\mathrm{CV}_{t}$ when $\mathrm{b}$ changes can be gained by repeatedly substituting in the transition equation for individual wealth, (11), to yield, for $t \geq 1$ : 
(31) $L_{t}=\theta \sum_{i=0}^{t} \delta^{i}\left[(1-a) E_{t-i}+G_{t-i}\right]+\underline{\theta} \delta \sum_{i=t+1}^{t+1} \sum^{\infty}{ }^{i-(t+1)}\left[(1-\underline{a}) E_{t-i}+G_{t-i}\right]$

and recalling that endowed after tax earnings, $f_{t}=(1-a) E_{t}+G_{t}$. As $t$ approaches infinity and the new steady state is approached. (31) becomes: (31. ) $L_{t}=\theta \sum_{i=0}^{\infty} \delta_{t-i}^{i}$

Thus, the current lifetime wealth of an individual dynasty in steady-state is simply a geometrically-declining distributed $\mathrm{lag}$ of the after-tax endowments of all generations up to (and including) the present. During the transition to the new steady-state this lag structure is more complicated, as (31) shows.

The implications of (31) and (31') for the time path of inequality are as follows. Suppose first that a tax of any kind (with the exception of a pure earnings $\operatorname{tax}$ ) was introduced at $t=0$ into a zero-tax world and the proceeds thrown away rather than redistributed as G. Then Davies (1986), Proposition 1, has shown, using $\left(31^{\prime}\right)$, that steady-state inequality must rise. The intuition is as follows. First, note that whatever increase in a occurs has no effect on inequality since, with $G$ fixed at zero, all $\underline{L}_{t}$ 's are reduced proportionally. Second, note that the strength of intergenerational accumulation, $\delta$, must fall. In the lag structure of (31'), this places relatively more weight on the endowments of recent ancestors in determining current income, and thus reduces the intergenerational averaging of "luck".

Now consider the adjustment path of inequality when tax proceeds are redistributed. Since $G_{t}$ jumps upward in period zero, but there is as yet little change in the intergenerational averaging of luck (the new $\delta$ has prevailed for only one period), inequality in lifetime wealth probably falls 
(indeed it must in the pure earnings and lifetime wealth tax cases), as will the inequality in endowed after tax wealth, $\underline{L}_{t}=(1-a) E_{t}+G_{t}$. In the following period $(t=1), L_{t}$ is an average of all current and past $L_{t}$ 's, including that in $t=0$. Even though the transfer payment, $G_{t}$, is lower at $t=1$ than at $t=0$, inequality could still fall relative to $t=0$ because $L_{t}$ is now an average that includes two generations in which $G_{t}$ is above its level at $t=-1$. In other words, the reduction in inequality that occurred in the impact generation is "passed on" through inheritances and augments the direct reduction in inequality that occurs through transfers among the members of the next generation. Thus, inequality may fall for several generations after a tax increase before the fall in $G$ and the decline in intergenerational averaging of luck are sufficient to counteract the above tendency. This is borne out both in the analysis of the separate cases below and the numerical examples of section IV.

\section{Lifetime Wealth Tax:}

If $a=b$ the behavior of $C V$ in the impact generation is easily derived from (17) and $\left(28^{\circ}\right)$ :

(32) $\frac{\mathrm{CV}}{\underline{\mathrm{CV}^{*}}}=\frac{1-b \theta}{1-\underline{b \theta}}$

Thus, as long as tax revenues increase with the tax rate in the impact period (i.e. we are not beyond the peak of the "Laffer curve" in the short run), the decline in the standard deviation of wealth will outweigh the decline in the mean in the impact generation, and inequality will fall. This is true even though the tax increase is preannounced and fully anticipated, and regardless of the parameters of individuals' utility functions. 
The appendix shows that in the $a=b$, lifetime wealth tax case it is not only true that the CV must decline in the impact generation, but also that it always approaches its new steady-state value from below. Hence when an increase in lifetime wealth taxation leads to a drop in steady-state inequality we obtain "overshooting" as a general result.

The "overshooting" result implies that after an increase in the lifetime wealth tax, inequality must decline to a "trough", before beginning a climb to its new steady state level. The depth and timing of this trough are of obvious interest. As discussed above, there is reason to expect that inequality may continue to decline for a number of generations before "bottoming out". While numerous factors can affect the characteristics of this trough, one effect which may be of special interest is associated with the relative size of inheritances. The larger is $\bar{I}_{t}$ the greater will be $G_{t}$ relative to $\bar{E}$. Thus any redistributive scheme which taxes inheritances $(b>0)$ is likely to have a more equalizing impact on the $\underline{L}_{t}$ 's in the first few generations after the policy change given a larger $\bar{I}_{t}$. But it is this drop in inequality in $\underline{L}_{t}$ which may cause inequality of lifetime wealth to continue to fall beyond the impact generation. Thus by magnifying the drop in inequality of the $L_{t}$ 's, a larger

$\bar{I}$ may be expected to lengthen and deepen the drop in lifetime wealth inequality on the way to the trough.

The possible significance of $\overline{I_{t}}$ for redistributive success in the short-run is especially interesting since it may well be at odds with the long-run picture. In a comparison of steady states there is some expectation 
that, since inheritances are equalizing, the larger they are to begin with the greater the chance of a perverse long-run effect. That is, the more important is inheritance in the initial steady state the greater appears to be the scope for interference, with the equalizing role of intergenerational transfers.

There is thus a possibility that situations where redistribution works well in the short-run may also often be cases where it works badly in the long-run.

\section{Inheritance Tax:}

There are two points we can make about the contrast between the behavior of $\mathrm{CV}_{t}$ under the lifetime wealth tax and an increase in the inheritance tax rate, $b$. Assuming that we start with $a=b$, a rise in $b$ alone will lead to the same time path of $\bar{L}_{t}$ (as if a rises along with $b$ ), but $v_{t}$ will be everywhere higher than in the lifetime wealth tax experiment. Thus the new steady-state $\mathrm{CV}_{t}$ will exceed that under a lifetime wealth tax, and $\mathrm{CV}_{t}$ will also be higher at all points in transition.

The second point that can be made is perhaps more interesting. This is that, even if $\mathrm{CV}^{*}<\underline{\mathrm{CV}}$, the tendency to overshoot CV* is reduced, compared with the lifetime wealth $\operatorname{tax}$ case. Given $\underline{v}^{*}$ and $v^{*},(27)$ indicates that $v_{t}$ will be bounded from below by the path that would be followed with $\mathbf{a}=\mathbf{b}$.

\section{Lifetime Income Tax:}

It is difficult to obtain analytical results for the behavior of $\mathrm{Cv}_{t}$ in the lifetime income tax case. It is also hard to construct meaningful comparisons with the lifetime wealth tax case if, e.g., some kind of equal revenue yield comparison is desired. However, two points about the 
transition can be made. First, as we noted, for given $\underline{v}$ and $\bar{v}^{*}$, the $v_{t}$ transition path is bounded above by the $\phi=\Phi$ path. Thus, the degree of overshooting under the lifetime income tax has a tendency to be greater than under the lifetime wealth tax.

A final point of some interest is that the overshooting result is not only preserved under the lifetime income tax, but in any case where $\phi$ declines as $b$ rises--for example where $a$ and $b$ are in a constant ratio, and 0 $<\mathrm{b} \leq \mathrm{a}$. Thus while there is not overshooting in the pure earnings tax case there is overshooting as soon as we introduce inherited wealth into the tax base, with however small a weight.

\section{INTERPRETATIONS and EXAYPLES}

The goal of this section is to compute examples of transition paths based on "realistic" parameter values in our model. Since the implementation of the model requires us to be more precise about the interpretation of various quantities in it, we begin with a discussion of two related issues: (1) can transfers of human capital ${ }^{12}$ and optimal human capital investment decisions be incorporated into the model, and (2) should programs like public support for education be thought of as intergenerational transfers of human capital or as something else?

\section{Human Capital in the Model}

The easiest way to re-interpret the current model to include human capital is that used by Becker and Tomes (1979). In their formal analysis, they treat physical and human capital as bearing the same fixed, exogenous rate of return. Thus the two kinds of investments are perfect substitutes and only total investment, unlike its composition, is determined in the model. 
The total level of investment does not depend on any efficiency considerations, but only on the parent's degree of altruism toward his or her child.

In the Becker-Tomes interpretation, $E_{t}$ thus represents the child's "endowed" earnings (what he would earn with no human capital investment), and $I_{t}$ is composed of both financial inheritances and the incremental earnings due to bequests of human capital. Two kinds of tax schemes seem realistic in this world: a lifetime wealth $\operatorname{tax}(a=b)$, and a lifetime "income" tax, which taxes the returns to both human and physical capital but not the principal transferred. $^{13}$ Regardless of the tax scheme used; however, note that this interpretation requires the tax rates imposed on human vs nonhuman components of $I_{t}$ to be identical, if both forms of inheritance are to be observed in equilbrium.

Another way to incorporate human capital into the model, is, we feel, more realistic because it incorporates the fact that there may be some curvature in the human capital production function, and thus an efficient level of investment in it. This incorporates the notion that some basic investments would be provided even by purely selfish parents, simply because they are jointly efficient for parent and child. ${ }^{14}$ Assume that the child's human capital is produced according to:

(33) $x_{t}=h\left(s_{t}, A_{t}\right), h_{s}>0, h_{A}>0$

where $x_{t}$ is the amount of human capital produced, $s_{t}$ the amount of time spent acquiring human capital, and $A_{t}$ is endowed "ability". Human capital is measured such that the market value of one unit of capital is a dollar of discounted lifetime earnings, and, for simplicity, we imagine the child sells 
his human capital in one "lump" as soon as the entire stock has been accumulated. 15

Now if the financial cost per instant of human capital accumulation is $F_{t}$, and this expense is deductible from earnings for tax purposes, the efficient investment decision solves:

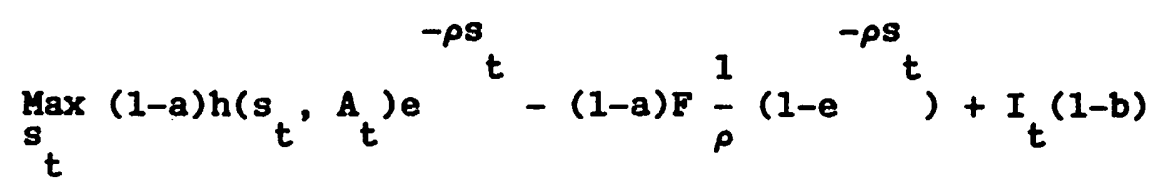

where $p$ is the instantaneous rate of return on physical capital. (Note that, since all taxes in this model are based on lifetime income and wealth, this discount rate is unaffected by taxes.)

The solution to (34) is unaffected by $a$ and $b$. If we further assume that $\rho$ and $F$ are constant over time, the solution can be written simply as $s_{t}\left(A_{t}\right)$, regardless of the tax scheme which is in place. Finally, $s_{t}\left(A_{t}\right)$ implies the existence of a monotonically increasing function, $E_{t}\left(A_{t}\right)$ which gives the optimal level of lifetime earnings before tax, but net of schooling costs, for an individual of ability $A_{t} \cdot$ Thus efficient human capital investment decisions as described in (34) can be incorporated into the current model by assuming that each child's optimal earnings, $E_{t}\left(A_{t}\right)$ are related to his parent's optimal earnings, $E_{t-1}\left(A_{t-1}\right)$, via the regression mechanism in (20). 16

Thus, in our interpretation of the model, $E_{t}$ can be interpreted straightforwardly as the actual present value of lifetime earnings. $I_{t}$ can be positive or negative, and can be thought of as a purely financial transfer. Whether it is "actually" used to support the child's consumption while in school, to pay tuition fees, or simply consumed is immaterial, since the level of human capital investment is invariant to $I_{t}$ and is determined purely by 
efficiency considerations. In this framework, all four types of taxes considered in the paper may have realistic empirical counterparts, although it is important to recall that inheritances should be thought of as the total net dollar transfer from parent to child. Differential taxation of human and physical capital are also possible.

\section{State-financed education}

In both the BT interpretation and our own, the question of how to interpret state-funded education arises. In both cases, there are three possibilities, depending primarily on how the expenditure is financed. Suppose first that public education (whether seen as a direct gift of human capital or a cash grant to cover tuition costs) is financed by a head tax on parents, and that the amount of education provided free of charge by this method is inframarginal for all families. Then it is clear that public education is an implicit transfer from each parent to his or her child, and that each parent simply "tops up" his transfers to his child to the utility maximizing level privately. In other words, the value of public education should be counted as part of $I_{t}$.

Second, imagine that public education is now financed by a head tax which is levied on the children being educated, but again is inframarginal for all children (in reality, this would require issuing government debt that is repaid by the children themselves later). Now, state financed education is not part of $I_{t}$ and in fact should not appear anywhere in the formal model. Finally, imagine that instead of a head tax, the government uses the actual tax system in place (the $a^{\prime} s$ and $b^{\prime} s$ ) to finance education. If the tax is levied on the children being educated, then as long as educational expenditures are equivalent to universal cash grants, they are properly 
thought of as part of the transfer, $G_{t}$. This of course breaks down, as do the above two interpretations, if subsidies to education exceed the amount which children would otherwise spend in education, or lower the incremental private cost of a year of education at the margin, in which cases they induce inefficiently high schooling levels. 17

\section{Examples}

The transition paths computed in Tables 1-5 use a specific functional form of utility (6) given by

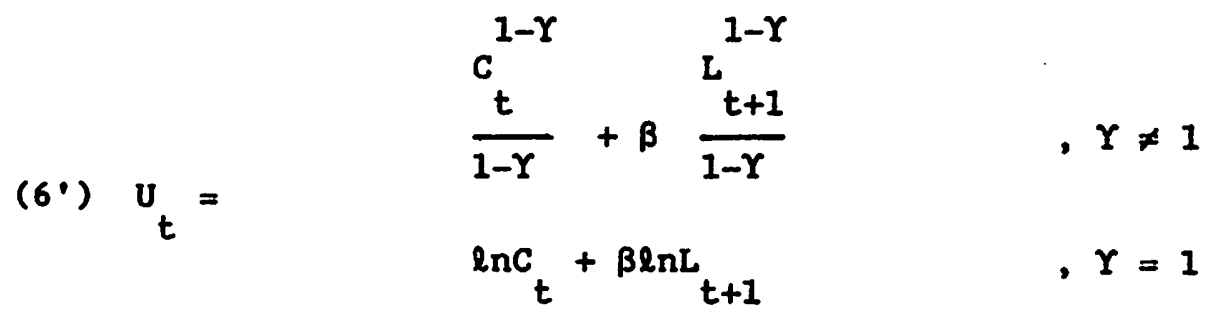

The elasticity of substitution between $C_{t}$ and $L_{t+1}$ is $0=\frac{1}{Y}$.

The parameter values in Tables 1-5 are meant to represent two situations--one in which the ratio of mean inheritances to income, $\bar{I}$

$t$, is relatively low, and one where it is high. The first, represented $\overline{\mathrm{L}}$

in the "base" case of tables 1 and 2 , is meant to correspond to a world in which inheritances contain little or no human capital component; thus for example public education is not part of $I_{t}$. The parameter values are those used in Davies (1986): $\sigma=0.5, v^{2}=0.4, \beta=0.8$; and $r=2.67$ per 25-year-1ong generation, which corresponds to a value per year of $1.04 .^{18}$ If the tax rate 
is $20 \%$, this produces an $\frac{\overline{I^{*}}}{\bar{L}^{*}}$ of 0.13 and 0.04 under the lifetime income and

wealth taxes respectively, which correspond to the low values found empirically by Blinder (1974) and Davies (1982).

The other cases we examine are meant to correspond to a situation where $I_{t}$ includes large human capital components, such as public education. This is accomplished, in turn, by raising $\mathbf{r}$ (Table 3 ), $\delta$, (Table 4), or $\beta$ (Table

5) 19 from its base case level in such a way as to given an inheritance ratio, $\bar{I}$

$\frac{t}{\bar{L}_{t}}$ of 0.5 two generations after the policy change has occurred. 20 The

values used are: $r=1.046$ (on an annual basis), $\sigma=1$, and $\beta=.625$.

The results of these experiments are discussed below in turn. Before proceeding, however, it is perhaps worth noting that, in our examples, we have not needed to make any assumptions about the distribution of shocks to $\varepsilon_{t}$ except that the distribution is stationary with mean zero. ${ }^{21}$ Indeed the results hold for all distributions with finite variance, regardless of the level of variance (since they are normalized with respect to $\mathrm{CV}$. )

Table 1 shows the transition of CV from its old, to its new steady-state value in the "base" case. For each of the four different tax bases we show what happens when tax rates of $10 \%$ and $20 \%$ alternatively are introduced in a world with zero taxes initially. These relatively low tax rates may reflect changes of a magnitude experienced in the real world. For example, if we took the tax share of national income as a guide we might view a $20 \%$ lifetime income tax rate as roughly reflecting current circumstances. However, it is 
important to keep in mind that it is only that element of the tax system which redistributes among the members of a cohort which is captured in our model, so that a lifetime income tax rate of, say, 10\% might be more "realistic". 22 Examining the alternative tax schemes of Table 1 in turn, we find:

(i) Inequality asymptotes smoothly to the new steady state under the earnings tax. With both tax rates three generations must pass before the CV has achieved half of its fall to the new steady-state.

(ii) The inheritance tax increases steady-state inequality, and there is only a brief period of one or two generations during which inequality initially declines.

(iii) The lifetime wealth tax reduces steady-state inequality, but considerably less than did the earnings tax levied at the same rate. Also, we find the overshooting phenomenon predicted in the previous section. With either tax rate inequality at first declines sharply, falling below its new steady-state level in the second generation subject to the tax. Inequality declines for four or five generations and then begins a long gradual climb to its new steady-state value.

(iv) Results under the lifetime income scheme are qualitatively similar to those under the lifetime wealth tax, but indicate somewhat more successful redistribution. The steady-state decline in the $\mathrm{CV}$ is greater and the trough in inequality occurs one or two generations later than in the lifetime wealth tax case.

Table 2, which shows how mean wealth behaves in transition, provides some help in understanding the results of Table 1 . The change in mean wealth reflects the strength of the reduction in intergenerational accumulation (if 
any) in response to the tax changes. As we would expect from the earlier analysis, the earnings tax has no effect. In contrast, each of the other three taxes produces a path for mean wealth which asymptotes monotonically to the new, lower, steady-state value. Half of the drop to the new steady-state level is accomplished in each case after three generations have been subject to the new tax.

Two important conclusions emerge from this discussion of the "central case". One is that not only may the attempt to redistribute inheritances be self-defeating in the long-run, its success in the short-run may be slight. The other is that redistribution using a lifetime income or lifetime wealth base can set in motion a trend towards declining inequality which persists for a long time--from four to six generations, that is from about 100 to 150 years, and that at least as much additional time elapses before inequality is reasonably close to its new steady state value. The latter conclusion indicates that the conjecture by Becker and Tomes that the small impact of the welfare state on measured inequality in the U.S. may be due to mechanisms captured by this kind of intergenerational model of income distribution needs to be assessed with some care.

Turning now to the departures from the base case examined in Tables 3-5, we note first their broad similarity to the central case results--redistribution is typically equalizing in the long run for all taxes but the inheritance tax, and inequality first falls and then rises. (It is worth noting that this is not true if $r, \beta$ or $\sigma$ are raised to even higher levels, generating extremely high $\frac{\bar{I}_{t}}{\bar{L}_{t}}$, in which case redistribution 
is typically disequalizing in the long run.)

In each of Tables 3-5 redistribution of earnings has the same steady-state impact as in the central case, but transition is slower. The reason is that as a proportion of mean wealth the tax base is smaller due to the higher inheritance ratio. For the inheritance, lifetime wealth, and lifetime income tax bases, we find in all cases that the new steady-state levels of inequality are higher than in the central case--indeed often steady-state inequality is increased by taxation. Remarkably, however, in all but one case (lifetime income base with $20 \%$ tax rate) inequality in the trough is lower than in the central case, and in all cases the $\mathrm{CV}$ in the trough is much lower relative to the ultimate steady-state $\mathrm{CV}$. We also find that with higher $r$ or $\beta$ the trough is generally delayed by a generation or two relative to the central case. In contrast, with higher o the trough actually comes about a generation earlier, because the higher elasticity of substitution implies greater sensitivity of saving rates with respect to the after-tax intergenerational rate of return. These results confirm the importance of

$I_{t}$ in determining the success of redistribution in the short-run, conjectured in the previous section.

Tables 3-5 thus have the interesting implication that if "inheritances" in this model are thought of as including transfers in human form, then redistribution works significantly better for the first three or four generations than when inheritance refers only to physical capital. Indeed, if we reject the possibility that the intergenerational elasticity of substitution is above 0.5 (life-cycle studies, such as that by Auerbach et. al., have recently been using intertemporal elasticities of substitution lower than 0.5 ) then, although redistribution works less well in the very long-run, 
it can produce lower inequality than in our central case for a long time. Table 3 shows that with $\mathbf{I}=1.046$ and lifetime wealth taxation at $10 \%$, for example, it is not until 15 generations have passed that the CV rises above its central case value.

\section{ALTERNATIVE BEQUEST HOTIVES}

At least five alternative possible motivations for bequests have been suggested. One is the imperfect annuity markets examined in Davies (1981). A second is parent's desire to "purchase" certain services such as visits and attention from children, examined in Bernheim, Shleifer and Summers' (1985) "strategic" bequests model. Third, parents may derive utility directly from the amount they bequeath, regardless of its effects on their children, for "demonstrative" reasons or because of the "warm feeling" given. Such bequests, like the two preceding kinds, are neither altruistic nor compensatory. Fourth, parents may derive utility only from the amount received by the child, in which case bequests are altruistic, but noncompensatory. Finally of course bequests may be altruistic and compensatory, as they are in the current model. This section briefly comments on how the effects of the second, third and fourth types of bequests above can be analysed via a minor modification of the present model.

Consider first "demonstrative" or "warm feeling" bequests, where $U_{t}=U\left(C_{t}, B_{t}\right)$, and the parent's budget constraint is $C_{t}+B_{t}=L_{t} \equiv z_{t}^{B}$. Define $\hat{I}_{t+1}=(1-b) I_{t+1}$ as the after-tax inheritance received by the child. Then homotheticity of $U$ implies $B_{t}=\theta^{B} L_{t}$, where $\theta^{B}$ is now invariant to tax and interest rates. Finally, note that $\tilde{I}_{t+1}=\tilde{r} \theta^{B} L_{t} \equiv \delta^{B} L_{t}$, where $\frac{\partial \delta^{B}}{d a}=0$ and $\frac{\partial \delta^{B}}{d b}<0$, as in our "basic" model. This allows us to 
derive the basic transition equation for an individual dynasty's wealth: (12') $L_{t+1}=\delta^{B} L_{t}+\left[(1-a) B_{t+1}+G_{t+1}\right]$

which is identical to (12) in all but two respects: The first is that $\delta^{B}$ replaces $\delta$. Since $\delta^{B}$ responds to changes in taxes the same way $\delta$ does, this will not change any of our qualitative predictions. Second, the coefficient $\theta$ on the square brackets in (12) is missing in (12'). This captures the only major change in the predictions of the model when "demonstrative" bequests occur: shocks to the child's after tax earnings or transfer payments are now reflected one-for-one in the child's lifetime wealth, rather than only by $\theta$ dollars per dollar of after-tax earnings. Before examining the implications of the above for the evolution of inequality in the model, consider now the "strategic" model of bequests, where $U_{t}=U\left(C_{t}, s_{t}\right)$ and $s$ represents services purchased from the child (presumably at the end of the parent's lifetime and beginning of the child's), and the altruistic, non-compensatory model $U_{t}=U\left(c_{t}, \hat{I}_{t+1}\right)$. Note first that, if the parent "purchases" $s_{t}$ from the child at a fixed price $p$ (which may be the outcome of bargaining) and we measure units of $s_{t}$ such that $p=1$, the two models are identical in the simple world considered here, since $s_{t}=\hat{p I}_{t+1} .^{23}$ Writing both models as $U_{t}=\left(c_{t}, \hat{I}_{t+1}\right)$, define the parent's budget constraint now as $C_{t}+{\underset{\tilde{r}}{t+1}}^{\frac{i}{r}}=L_{t} \equiv \dot{z}_{t}^{I}$. Homotheticity now implies

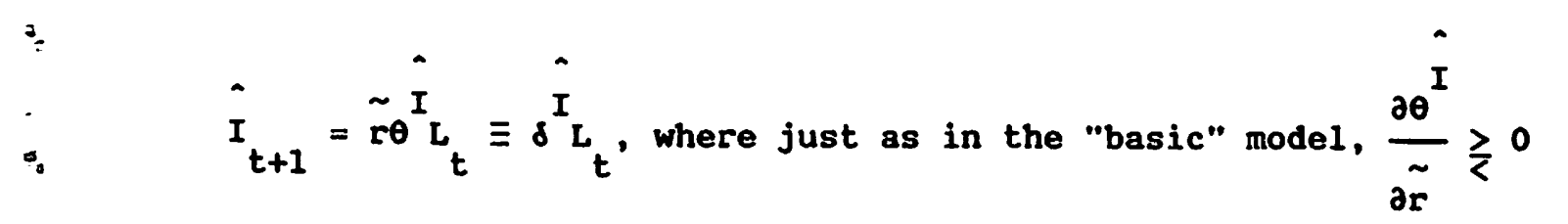


as $\sigma \frac{i}{<} 1 ; \frac{d \delta^{I}}{d a}=0$, and $\frac{d \delta^{I}}{d b}<0$. The transition equation for an

individual dynasty's wealth is now:

(12") $L_{t+1}=\delta L_{t}^{I}=\left[(1-a) B_{t+1}+G_{t+1}\right]$

which is the same as (12) and (12') except for $\delta \hat{I}$, which however responds to changes in $a$ and $b$ the same way as $\delta$ and $\delta^{B}$. Thus all three alternative models of bequests can be characterized by an individual transition equation identical to (12) with $\theta=1$.

What effects does this change in the model have on the transition paths of mean wealth and of inequality when taxes are introduced? steady-state mean wealth is now:

(14') $\bar{L}^{-*}=\frac{\overline{\mathrm{E}}(1-\mathrm{b})}{1-\mathrm{b}-\delta}$

which as before is unaffected by earnings taxation and falls with the inheritance tax rate, b. Solving for the time path of mean wealth after a tax increase at $t=0$ :

(161) $\bar{L}_{t}=\left(\frac{\delta}{1-b}\right)^{t}\left[\underline{L}^{-*}-L^{*}\right]+\bar{L}^{-*}$

which declines monotonically as before. Steady-state variance of wealth now becomes:

(24') $v *=\frac{(1-a)^{2}}{\left(1-\delta^{2}\right)} \frac{1+v \delta}{1-v \delta} \mathrm{V}(E)$ 
which now is always decreasing in both a and $b$. Solving for the evolution of variance after a tax increase:

$$
\begin{aligned}
& \text { (27') } v_{t}=v *+\delta^{t}\left[\underline{v} *\left[\delta^{t+2}+\delta^{2}\left(\frac{1}{\delta^{2}}-1\right) \frac{\phi}{\phi} \underset{\theta}{\underline{\theta}} \underline{t}_{t}\right]\right. \\
& \left.\left.-V *\left[\delta^{t+2}+\delta^{2}\left(\frac{1}{\delta^{2}}-1\right) D_{t}\right]\right\}+\frac{1}{r^{2}}\left[\delta^{t+2 \phi}-\frac{\phi}{\theta}-\frac{\phi}{\theta}\right] V(B) D_{t}\right]
\end{aligned}
$$

which is similar in structure to (27), and identical if $a=b$ and $\alpha=1$.

The steady-state coefficient of variation becomes:

$$
\text { (30') } \quad c V *=\frac{1-b-\delta}{\sqrt{1-\delta}} \cdot \sqrt{\frac{1+V \delta}{1-V \delta} \mathrm{cV}(\mathrm{B})}
$$

which again decreases with $a$, and is now in some sense more likely to decrease with $b$ since the ambiguity in $\theta$ is removed. Regarding the evolution of the coefficient of variation, two points can be made. First, the proof of "overshooting" in the Appendix applies directly to the new model if $\sigma=1$; otherwise the path of $\mathbf{C V}_{\mathbf{t}}$ is somewhat harder to characterize. Second, when $\mathrm{L}_{\mathrm{t}}$ is written as a weighted sum of all current and past endowments, as in (31), we obtain:

(31') $L_{t}=\sum_{i=0}^{t} \delta^{i}\left[(1-a) E_{t-i}+G_{t-i}\right]+\delta^{t+1} \sum_{i=t+1}^{\infty} \delta^{i-(t+1)}$ which has the same structure as before. Thus, the same kind of "cumulative" reduction in inequality for several generations after a tax increase is likely to occur, for the same reasons as before. 


\section{SUMAIARY}

This paper has examined the dynamic adjustment of a model of intergenerational income distribution with various bequest motives under alternative linear redistributive schemes. The latter are based on the taxation of earnings and inheritances, differing only in the relative rate at which these two components are taxed. With full costs of human capital investment deductible, and proportional taxation, there is an efficient level of earnings for each individual which is invariant with respect to tax. Thus taxes on earnings are in effect lump sum, and can be used to finance transfer payments in confidence that the result will be equalizing. In contrast, taxing inheritances--which may include the costs of upbringing and education, as well as "non-human" transfers--has complex and interesting effects here.

When a pre-announced redistributive tax on inheritances is implemented, we find that adjustment of inequality, as measured by the coefficient of variation of lifetime wealth, to its new steady-state value can take a long time. Indeed our results indicate that, in most realistic cases, inequality continues to fall for several generations after the tax change to a level below the new steady-state value before beginning to rise again. This occurs because the initial reduction in inequality is "passed on" through inheritances to following generations, and suggests that "steady-state" models of the perverse effects of redistribution may not help explain the apparently small decline in inequality which has occurred since the widespread introduction of the "welfare state" in some developed nations. 


\section{Appendix}

This appendix denonstrates that in the $a=b$ (lifetime wealth tax) case, $\mathrm{CV}_{t}$ always approaches from below its new steady-state level after an increase in the tax rate. This tells us much about the time path of $\mathrm{CV}_{\mathbf{t}}$ in transition--for example, in the case where cV* $<$ cV*, we see that inequality always overshoots its new steady-state value in transition.

Note first that since $\bar{L}_{t}$ declines monotonically, if we can show that


(Note that $C_{t}=\sqrt{\left.\frac{V_{t}}{\left(\frac{-}{L_{t}}\right)} \cdot\left(\frac{1}{\bar{L}}\right) .\right)}$

The behavior of $\bar{L}_{t}$ is of course much simpler than that of $v_{t}$. In particular, from (19), the difference between $\overline{\mathrm{L}}_{t}$ and its new steady-state value, $\bar{L}^{-*}$, declines according to:

(A1) $\bar{L}_{t}-\bar{L}^{*}=\left(\underline{L}^{-*}-\bar{L}^{-*}\right)\left(\frac{\delta}{1-b \bar{\theta}}\right)$

so that $\overline{\mathrm{L}}_{t}-\overline{\mathrm{L}}^{*}$ declines at the constant proportional rate:

(A2) $\frac{\left(\bar{L}_{t}-\bar{L}^{-*}\right)-\left(\bar{L}_{t+1}-\bar{L}^{-*}\right)}{\left(\bar{L}_{t}-\bar{L}^{-*}\right)}=1-\frac{\delta}{1-b \theta}$

Turning to $v_{t}$, matters are not so simple. From (30), when $a=b$ :

(A3) $v_{t}-v^{*}=\left(\underline{v}^{*}-v^{*}\right)\left(\delta^{2}\right)^{t+1}+\delta^{t+2} D_{t}\left[\left(\frac{1}{\delta^{2}}-1\right) \underline{v} x-\left(\frac{1}{\delta^{2}}-1\right) v^{*}\right]$ 
Wote that if the second term could be ignored, $v_{t}-v *$ would decline at a constant proportional rate $1-\delta^{2}$ that is faster than that of $\left(\bar{L}-\bar{L}^{-\star}\right)$. (The stability condition for $\bar{L}_{t}$ in (18) guarantees $\delta^{2}<\frac{\delta}{1-b \theta} \cdot$ ) of course if the second term also declines at a faster percentage rate than $\bar{L}_{t}-\bar{L}^{-*}$ then we still have $v_{t}-\vec{V}^{*}$ falling relative to $L_{t}-\vec{L}^{-*}$. What we show next is that there is always some $t$ beyond which both terms in (A3) decline faster, proportionally, than $\bar{L}_{t}-\bar{L}^{-*}$.

The proportional rate of decline of the second term in the RHS of (A3)

is $1-\delta \frac{D_{t+1}}{D_{t}}$. This will be greater than the proportional rate of decline of $\mathrm{L}_{t}-\overrightarrow{\mathrm{L}}^{-\star}$ if

(A4) $\frac{D_{t+1}}{D_{t}}<\frac{1}{1-b \theta}$

Now, $\frac{1}{1-b \theta}>1$, so that $\left|D_{t}\right|$ declining is sufficient for (A4) to hold.

To examine the behavior of $D_{t}$, let $v>\delta$, without loss of generality. Note that:

(A5) $\Delta D_{t} \equiv D_{t+1}-D_{t}=\frac{1}{v-\delta}\left[v^{t+1}(v-1)-\delta^{t+1}(\delta-1)\right]$

For $\Delta D_{t}<0$ we need:

$$
v^{t+1}(1-v)-\delta^{t+1}(1-\delta)>0
$$


or

(A6) $\left(_{\delta}^{v}\right)^{t+1}>\left(\frac{1-\delta}{1-v}\right)$

Now, $\left(\frac{1-\delta}{1-v}\right)>1$ since $v>\delta$, by assumption. But since $\frac{v}{\delta}>1$ as well,

the inequality must be satisfied for sufficiently large $t$.

We have now shown that beyond some $t, v_{t}$ - v* must decline at a faster

\% rate than $\bar{L}_{t}-\bar{L}^{-*}$. Let the critical $t$ beyond which this is true be denoted

k. We can now demonstrate the following:

Proposition: There is some $t>k$ such that

$\bar{L}_{t}<\overline{L^{*}}$

Proof: Note first that $\frac{v_{t}}{\bar{L}_{t}}<\frac{v^{*}}{\bar{L}^{*}}$ if and only if $\frac{v_{t}-v^{*}}{\bar{L}_{t}-\bar{L}^{*}}<\frac{v *}{\bar{L}^{*}}$. This is

implied by

$$
\frac{v_{t}}{L_{t}}=\frac{\left(v_{t}-V^{*}\right)+V^{*}}{\left(\bar{L}_{t}-\bar{L}^{*}\right)+\bar{L}^{*}}<\frac{v^{*}}{\bar{L} *}
$$

since $v_{t}-v^{*}, \bar{L}_{t}-\bar{L}^{-*}>0$. Now it can be shown that

$\lim _{t \rightarrow \infty} \frac{v_{t}-v^{\star}}{\frac{L}{t}-\bar{L}^{-*}}=0$, so that the desired inequality will be met for some

finite t. To do so, write: 
$\frac{v_{t}-v^{*}}{L_{t}-L^{-*}}=\theta_{t-1}\left(\frac{v_{t-1}-v^{*}}{L_{t-1} .^{-L^{-*}}}\right), \forall t$,

or

$$
\frac{v_{t}-v^{*}}{L_{t}-L^{*}}=\left(\sum_{i=t-k}^{\infty} \theta_{i}\right)\left(\frac{v_{t-k} v^{*}}{L_{t-k}-L^{-*}}\right) .
$$

Now, letting $t$ approach infinity,

$$
\lim _{t \rightarrow \infty}\left(\frac{v_{t-v^{*}}}{L_{t}-\bar{L}^{-*}}\right)=\left(\sum_{i=t-k}^{\infty} \theta_{i}\right)\left(\frac{v_{t-k^{-v}}}{\bar{L}_{t-k^{-L^{-*}}}}\right)
$$

since $\theta_{i}<1$ for $i \geq t-k$, the RHS $=0$.

Q.B.D. 
NOTES

1. There are five relatively minor differences between our model and theirs. First, we consider only one kind of "luck", which is fully observed by parents while they consider two, one of which may not be observed by parents. Second, we do not introduce an "unsystematic" component to taxes. Third, we prefer to think of the model as one of one child per family rather than dealing with family wealth each generation. Fourth, we consider two tax schemes in addition to those analysed in BT. Finally, our interpretation of the human versus nonhuman capital composition of inheritances in section IV differs somewhat from theirs.

2. As noted earlier, Davies (1986) is in turn similar in most important respects to Becker and Tomes (1979). Here we follow the notation of Davies (1986), to which the reader may refer for a fuller discussion of the basic model. The model presented here differs from that of Davies (1986) (a) by assuming a particular structure for intergenerational earnings mobility, and (b) abstracting from wage growth.

3. Alternatively, the model can be thought of as one of primogeniture in which the resources of each dynasty are passed on from one family to another through a single descendant. Introducing bequests to more than one child would complicate the model, but would not necessarily lead to the absurd conclusions that arise when sexual reproduction is introduced into the model of Bernheim and Bagwell (1985). This is because our formulation of utility in (6) as depending on one's own child's wealth, not consumption, can operate so as to sever altruistic links between dynasties at any point in time. 
4. "Lifetime income" is the sum of earnings and interest accruing to generation $t$. $I_{t}$ includes interest earned on the bequest, $B_{t-1}$, passed on by the previous generation. Thus interest received is

$$
(r-1) B_{t-1}=\left(\frac{r-1}{r}\right) I_{t} \text {. }
$$

Note that the first two schemes are those considered by Becker and Tomes (1979).

5. Administrative and compliance costs are ignored. These could produce

$$
\begin{aligned}
& \bar{L}_{t}<\bar{E}_{t}+\bar{I}_{t} \text {, and a less equalizing result of redistribution due to } \\
& \text { lower } G_{t} \text {. }
\end{aligned}
$$

6. Empirical confirmation that bequests are inversely related to the mean eamings of children in a family was found by Tomes (1981). However, the compensatory nature of bequests has come into question by those who have pointed out that equal division of estates between heirs is a typical pattern, (see, e.g., Menchik, 1980 and 1984), and by Bernheim, Shleifer, and Summers (1985) who claim to find empirical support for an alternative, "strategic", bequest behaviour. Interestingly, both these models can be analyzed via a minor modification of the present model presented in section $v$, with few effects on our conclusions. A more difficult exercise would be to assume $U\left(C_{t}, U_{t+1}\right)$ as in Laitner (1979a, b), who analyzes income distribution, but without incorporating taxes and transfers. Unfortunately, this has the inconvenient feature of forcing us either (a) to assume fully operative altruistic links with an infinite series of descendants for each family, which seems implausible, or (b) to endogenize the probability that such a chain will 
be broken at any point, which seems intractable. Perhaps for this reason, other authors (e.g. Ioannides and Sato, (1985) exploit the U(C $t^{\text {, }}$ $\mathrm{L}_{t+1}$ ) approach as well.

7. See Davies (1986) for a demonstration of the points noted in this paragraph.

8. The simplest way to see this is by drawing a phase diagram of (23): since all the coefficients in (23) are unchanged for $t \geq 0$, and $(v \delta)^{t+1}$ decreases over time, $v_{t}$ declines monotonically to $v^{*}$ from any initial point above the new steady state.

9. If $\delta=\delta$, equation (24) implies $\frac{v^{*}}{\underline{v}^{*}}=\frac{\phi}{2}<1$. Solving (24) for $v(E)$, substituting into (27), evaluating at $t=0$ and rearranging yields $\frac{v}{\underline{v}^{*}}=\frac{\Phi}{\Phi}+\left(1-\frac{\Phi}{\Phi}\right)\left\{\delta^{2}-\frac{\left(1-\delta^{2}\right)(1-v \delta)}{(1+v \delta)} \frac{\Phi}{\Phi}\right\}$.

It is then straightforward to verify that $\frac{v_{0}}{\underline{v}^{*}}>\frac{v^{*}}{\underline{v}^{*}}$, i.e. $v_{0}$ is above the new steady state value, $v *$.

10. From (8) and (9) note that $C_{t}$ and $L_{t+1}$ are proportional. Thus the relative inequality of wealth for generation $t$ must equal that of consumption for the previous generation. (Note that this statement applies for any scale-independent inequality index, not just the CV.) In steady-state this equality means that inequality of wealth equals that of consumption. In transition, it has the interesting consequence that changes in consumption inequality anticipate those in wealth inequality by one generation. 
11. Tomes (1981, footnote 1, p. 930) confirms that the same result holds in the Becker-Tomes model.

12. By a "transfer of human capital" we mean a parental expenditure on a child's upbringing or education.

13. A lifetime income tax could be implemented by starting with a lifetime wealth tax and making the parent's investments in the child's education as well as the principal amount of a financial inheritance deductible from the child's "taxable wealth". Pure taxes on $E_{t}$ or $I_{t}$ do not appear to have such plausible empirical counterparts here.

14. This contrasts with Becker and Tomes informal discussion of human capital (pp. 1180-81) and the formal treatment in Tomes (1981), in which the level of human capital investment will be inefficient whenever parents are insufficiently altruistic towards their children. (Investment in human capital is not carried to the point where its marginal return is equal to that physical capital.) Presumably this occurs in their model because they are ruling out negative bequests of physical capital. Lazear (1983) discusses this problem and estimates its empirical importance.

15. This is simply to avoid the inconvenience of a fixed horizon for the individual, which simply adds expository noise to the analysis without significantly affecting the conclusions.

16. Given the production function for human capital, the implied autoregression mechanism for $A_{t}$ can be recovered from the assumed process for $E_{t}$. For example, if $F=0$, a production function of the form $h(s, A)=\exp \left[C_{1} s-\frac{2}{2 A} s^{2}\right], C_{1}, C_{2}>0$ yields the optimal invest- 
ment rule $s_{t}\left(A_{t}\right)=A_{t}\left(\frac{C_{-p}}{C_{2}}\right)$. Substituting back into the definition of $E_{t}$ yields $E_{t}=\exp \frac{C_{1}^{2}-p}{2 C_{2}} A_{t}$. Thus in this case linear regression of $E_{t}$ to its mean implies linear regression of $\exp A_{t}$ to its mean.

17. On the other hand, if (contrary to what we have assumed) tuition expenditures are not completely tax deductible, the subsidies to education may just of fset the underinvestment in education due to the earnings tax, as Johnson (1984) has argued.

18. Empirical evidence on intertemporal substitution, which is analagous to $\sigma$, is found in Davies (1981, pp. 573-4), and Auerbach et al. (1983, p.89). Blinder (1976, p. 621), Griliches (1979) and Taubman (1976, p. 867) all discuss what $v$ should be. More detailed discussion of these estimates and the parameter values chosen here is available in Davies (1986).

19. Changes in $v$ from its base case level were also examined. The results are not reported here, since our results appear to be quite insensitive to large changes in $v$.

20. Initially, we chose the new $r, \delta$, and $\beta$ to give $\frac{\bar{t}_{\bar{L}}}{\bar{L}_{t}}=0.5$ in the new steady state. However, the result was implausibly high values of $\frac{\bar{t}}{\bar{L}_{t}}$ for both the initial (no tax) steady state and many 
generations after redistribution was introduced. Our choice of the period in which to aim for $\frac{\bar{t}_{t}}{\bar{L}_{t}}=0.5$ was based on the notion that the welfare state has been with us for about two generations.

21. Distributions with negative domains like the normal are, of course, somewhat implausible, but nevertheless formally consistent with the current analysis.

22. Many benefit-related taxes are largely non-redistributive. Other elements of the system, such as the social security system, to a large extent redistribute between age groups, that is across cohorts, rather than among the members of a single cohort.

23. Of course, this ignores all the interesting incentive-compatibility issues considered in Bernheim, Shleifer and Summers (1985) by simply assuming that market-type transactions can be enforced between parent and child. Since this is true in equilibrium in their paper, and incentive-compatibility constraints are not binding in the equilibrium they consider, it seems a reasonable adaptation of their model for our purposes. 


\section{References}

Atkinson, Anthony B., "Inheritance and the Redistribution of Wealth," in G.H. Heal and G.A. Hughes (eds.) Public Policy and the Tax System (London: Allen and Unwin, 1980).

Auerbach, Alan, J., Laurence J. Kotlikoff, and Jonathan Skinner, "The Efficiency Gains From Dynamic Tax Reform," International Economic Review 24 (1) (February 1983): 81-100.

Becker, Gary S., and Nigel Tomes, "An Equilibrium Theory of the Distribution of Income and Intergenerational Mobility," Journal of Political Economy 87, No. 6 (December 1979): 1153-89.

Bernheim, B. Douglas; and Bagwell, Kyle, "Is Everything Neutral?" mimeo, Stanford University, May 1985. ; Shleifer, Andrei; and Summers, Lawrence H., "The Strategic Bequest Motive," Journal of Political Economy, 93 (December 1985): $1045-76$

Blinder, Alan S., Toward an Economic Theory of Income Distribution (Cambridge, MA: MIT Press, 1974). , "Inequality and Mobility in the Distribution of Wealth," Kyklos XXIX (1976): 607-638.

Davies, James, B., "Uncertain Lifetime, Consumption, and Dissaving in Retirement," Journal of Political Economy 89, No. 3 (June 1981): 561-577.

- "The Relative Impact of Inheritance and Other Factors on Economic Inequality," Quarterly Journal of Economics 47 (August 1982): $471-498$. 
Davies, James B., "Does Redistribution Reduce Inequality?" Journal of Labor Economics, July 1986.

Griliches, Z., "Sibling Models and Data in Economics: Beginnings of a Survey," Journal of Political Economy LXXXVII (October 1979 Supplement): $\$ 37-\$ 64$.

Ioannides, Yannis M., "Heritability of Ability, Intergenerational Transfers and the Distribution of Wealth," School of Management, Boston University, mimeo (February 1983).

Ioannides, Yannis M. and Ryuzo Sato, "A General Equilibrium Theory of the Distribution of Wealth and Intergenerational Transfers," School of Management, Boston University, mimeo (March 1982).

Johnson, G., "Subsidies for Higher Education," Journal of Labor Economics 4, July 1984 .

Laitner, J., "Household Bequest Behavior and the National Distribution of Wealth," Review of Economic Studies XLVI, No. 3 (July 1979): 467-484, a. - "Household Bequests, Perfect Expectations, and the National Distribution of Wealth," Econometrica 47, No. 5 (September 1979): 1175-1193, b.

Lazear, E. , "Intergenerational Externalities," Canadian Journal of Economics 16, (May 1983): 212-228.

Kenchik, Paul L., "Primogeniture, Equal Sharing, and the U.S. Distribution of Wealth," Quarterly Journal of Economics, 94 (March 1980): $299-316$. 
Menchik, Paul L., "Unequal Estate Division: Is it Altrusm, Reverse Bequests, or Simply Noise?", paper presented at the Seminar on Modelling the Accumulation and Distribution of Wealth, Paris, September 1984. Stiglitz, "Equality, Taxation and Inheritance," in Krelle, Wilhelm and Anthony F. Shorrocks (ed.) Personal Income Distribution, (Amsterdam: North-Holland, 1978).

Taubman, P., "The Determinants of Earnings: Genetics, Family, and other Environments: A Study of White Male Twins," American Economic Review LXVI (December 1976): 858-870.

Tomes, Nigel, "The Family, Inheritance, and the Intergenerational Transmission of Inequality," Journal of Political Economy, 89 (October 1981): $928-58$. 
Table 1

$\mathrm{Cv}_{t}$ ' $\underline{\text { CVx }}$

\begin{tabular}{|c|c|c|c|c|c|c|c|c|}
\hline \multirow{4}{*}{$\begin{array}{r}\text { Tax Rate } \\
t=-1\end{array}$} & \multicolumn{8}{|c|}{ Tax Base } \\
\hline & \multicolumn{2}{|c|}{ Barnings } & \multicolumn{2}{|c|}{ Inheritances } & \multicolumn{2}{|c|}{ Lifetime Wealth } & \multicolumn{2}{|c|}{ Lifetime Income } \\
\hline & 0.1 & 0.2 & 0.1 & 0.2 & 0.1 & 0.2 & 0.1 & 0.2 \\
\hline & 1.000 & 1.000 & 1.000 & 1.000 & 1.000 & 1.000 & 1.000 & 1.000 \\
\hline 0 & .977 & .955 & .994 & .991 & .969 & .935 & .972 & .942 \\
\hline 1 & .956 & .914 & .996 & 1.000 & .947 & .892 & .950 & .897 \\
\hline 2 & .940 & .881 & 1.002 & 1.020 & .935 & .871 & .935 & .868 \\
\hline $\begin{array}{l}3 \\
4\end{array}$ & $\begin{array}{l}.928 \\
.919\end{array}$ & $\begin{array}{l}.857 \\
.839\end{array}$ & $\begin{array}{l}1.010 \\
1.018\end{array}$ & 1.043 & .930 & $\frac{.866}{.870}$ & .927 & .853 \\
\hline 5 & .913 & .826 & $\begin{array}{l}1.018 \\
1.026\end{array}$ & $\begin{array}{l}1.066 \\
1.086\end{array}$ & $\frac{.929}{.932}$ & $\begin{array}{l}.870 \\
.878\end{array}$ & $\begin{array}{r}.922 \\
.921\end{array}$ & $\frac{.846}{.844}$ \\
\hline 6 & $.908 *$ & .817 & 1.033 & 1.102 & .935 & .887 & .921 & $\frac{.0 .74}{.846}$ \\
\hline 7 & .906 & .812 & 1.040 & 1.116 & .938 & .895 & .922 & .849 \\
\hline 8 & .904 & $.808 *$ & 1.045 & 1.126 & .942 & .902 & $.924 x$ & .852 \\
\hline 9 & .902 & .805 & 1.049 & 1.134 & .945 & . 908 & .925 & .855 \\
\hline 10 & .902 & .803 & 1.052 & 1.149 & .947 & .912 & .926 & .857 \\
\hline 15 & .900 & .800 & $1.061 *$ & $1.154 x$ & $.955 *$ & $.924 x$ & .931 & $.865^{\star}$ \\
\hline 25 & .900 & .800 & 1.064 & 1.159 & .958 & .927 & .933 & .868 \\
\hline$\infty$ & .900 & .800 & 1.064 & 1.159 & . 958 & .927 & .933 & .868 \\
\hline
\end{tabular}

Table 2

$\overline{\mathrm{L}}_{\mathrm{t}} \underline{\underline{\underline{L}}}^{*}$

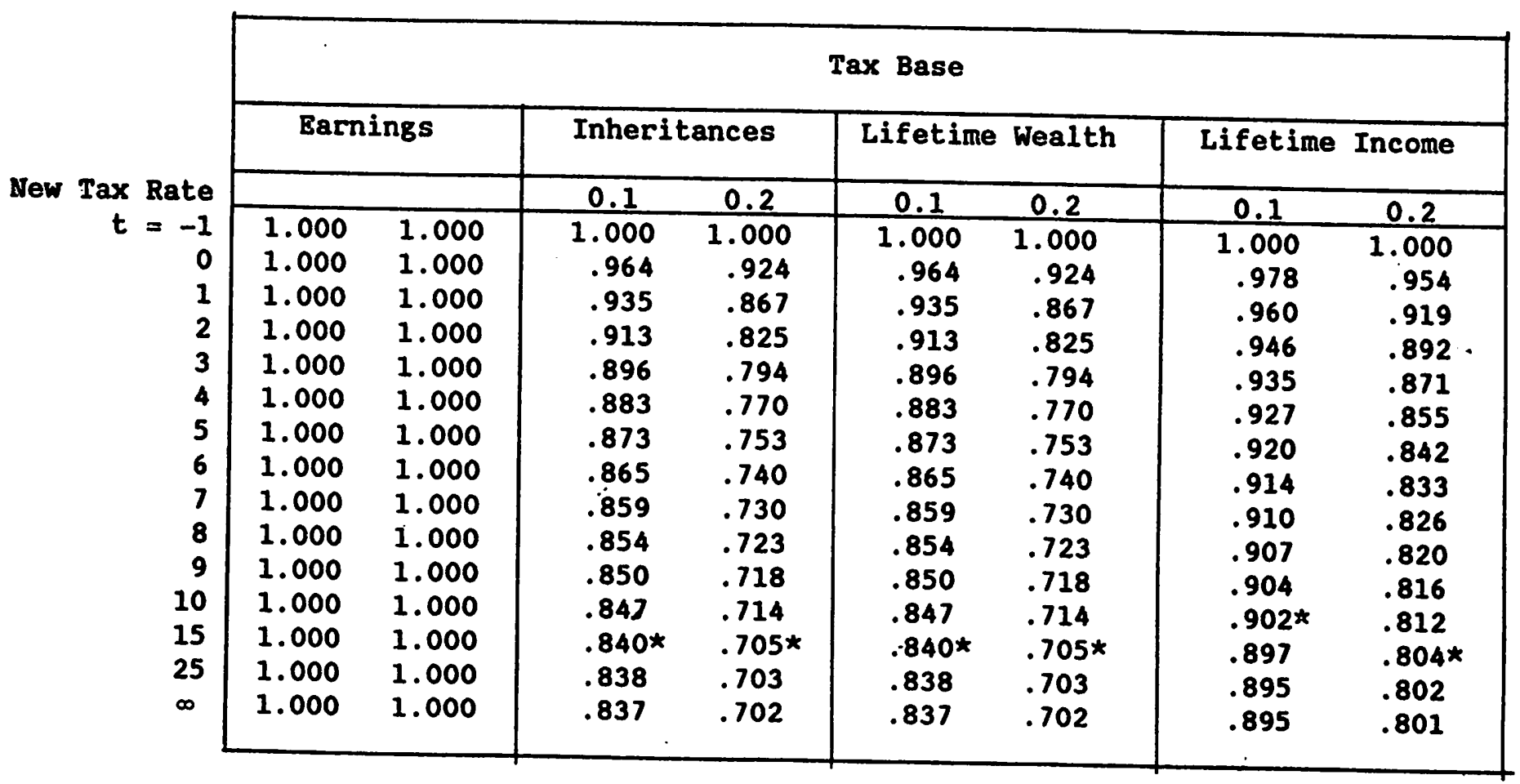

indicates a minimum

* - convergence to within $1 x$ of new steady-state value. 
Table 3

Higher r Case

$\mathrm{Cv}_{\mathrm{t}} / \mathrm{Cv}^{*}$

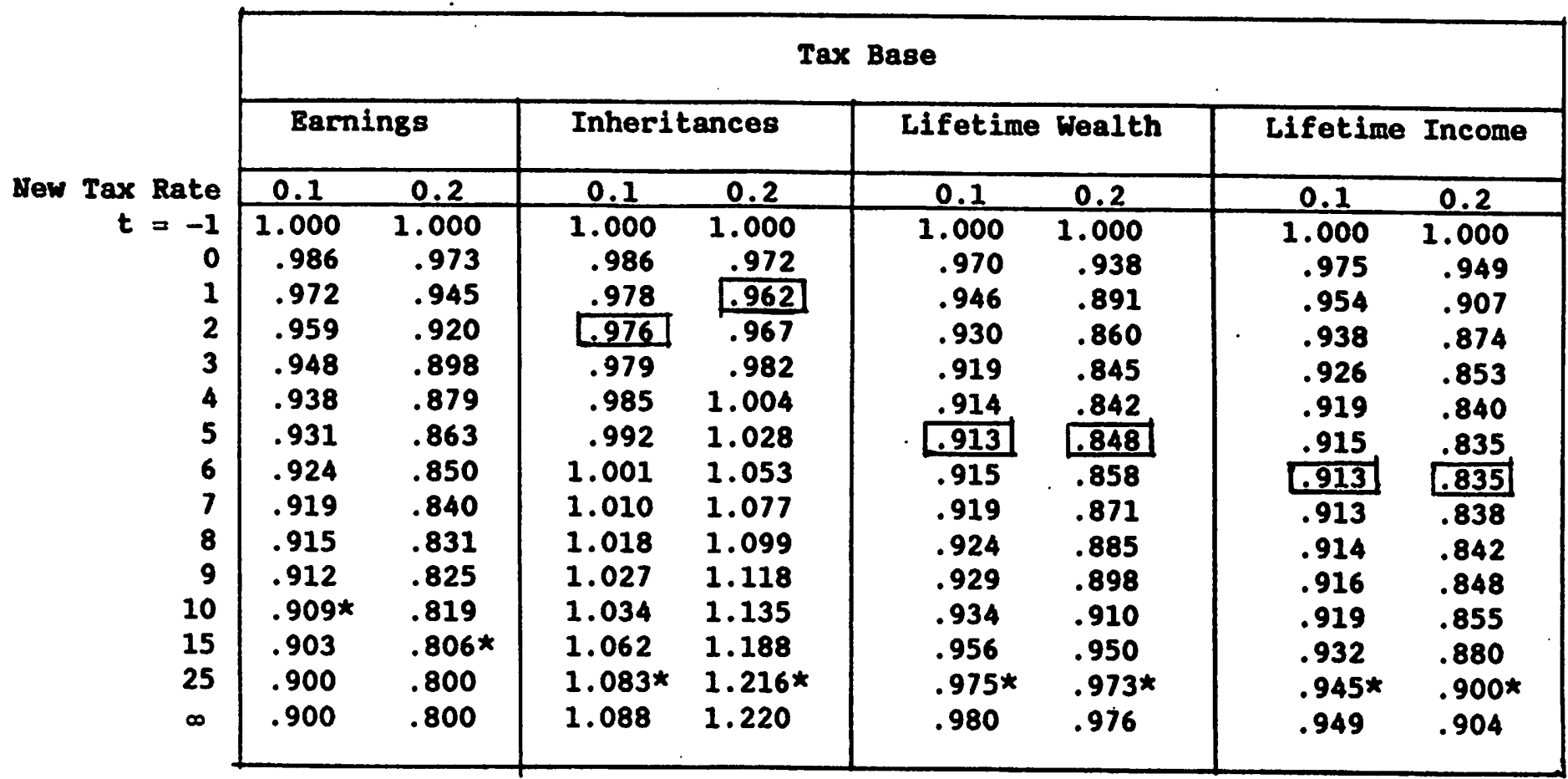

Table 4

Higher $\sigma$ Case

$\mathrm{CV}_{\mathrm{t}} / \underline{\mathrm{CV}}^{*}$

\begin{tabular}{|c|c|c|c|c|c|c|c|c|}
\hline \multirow{4}{*}{$\begin{array}{r}\text { Tax Rate } \\
t=-1\end{array}$} & \multicolumn{8}{|c|}{ Tax Base } \\
\hline & \multicolumn{2}{|c|}{ Earnings } & \multicolumn{2}{|c|}{ Inheritances } & \multicolumn{2}{|c|}{ Lifetime Wealth } & \multicolumn{2}{|c|}{ Lifetime Income } \\
\hline & 0.1 & 0.2 & 0.1 & 0.2 & 0.1 & 0.2 & 0.1 & 0.2 \\
\hline & 1.000 & 1.000 & 1.000 & 1.000 & 1.000 & 1.000 & 1.000 & 1.000 \\
\hline 0 & .987 & .974 & .981 & .966 & .967 & .933 & .974 & .947 \\
\hline 1 & .973 & .947 & .972 & .957 & .941 & .885 & .952 & .903 \\
\hline 2 & .960 & .922 & .972 & .973 & .925 & .861 & .935 & .872 \\
\hline 3 & .949 & .900 & .979 & 1.009 & .918 & .860 & .925 & .854 \\
\hline 4 & .940 & .882 & .991 & 1.057 & .919 & .878 & .919 & 8.848 \\
\hline 5 & .932 & .866 & 1.008 & 1.109 & .925 & .905 & .918 & .851 \\
\hline 6 & .926 & .853 & 1.025 & 1.159 & .935 & .937 & .920 & .859 \\
\hline 7 & .920 & .842 & 1.043 & 1.204 & .947 & . 969 & .924 & .871 \\
\hline 8 & .916 & .834 & 1.060 & 1.243 & .960 & .998 & .929 & .885 \\
\hline $\begin{array}{r}9 \\
10\end{array}$ & $\begin{array}{l}.913 \\
.910\end{array}$ & $\begin{array}{l}.827 \\
.821\end{array}$ & 1.076 & 1.276 & .972 & 1.022 & .935 & .898 \\
\hline $\begin{array}{l}10 \\
15\end{array}$ & $.903 x$ & .821 & 1.091 & 1.303 & .984 & 1.043 & .941 & .911 \\
\hline 15 & & $.807 \star$ & 1.140 & 1.373 & 1.026 & 1.098 & .966 & .954 \\
\hline 25 & .900 & .801 & $1.170 *$ & $1.397 *$ & $1.053 *$ & $1.118 *$ & $.987 *$ & $.978 x$ \\
\hline$\infty$ & $: 900$ & .800 & 1.176 & 1.399 & 1.058 & 1.192 & .993 & .982 \\
\hline
\end{tabular}

* - convergence to within 17 of new steady-state value. 
Table 5

Higher $\beta$ Case

$C v^{\prime}$ crt

\begin{tabular}{|c|c|c|c|c|c|c|c|c|}
\hline \multirow[b]{3}{*}{$\begin{aligned} \text { Tax Rate } \\
t=-1\end{aligned}$} & \multicolumn{8}{|c|}{ Tax Base } \\
\hline & \multicolumn{2}{|c|}{ Barnings } & \multicolumn{2}{|c|}{ Inheritances } & \multicolumn{2}{|c|}{ Lifetime Wealth } & \multicolumn{2}{|c|}{ Lifetime Income } \\
\hline & $\begin{array}{r}0.1 \\
1.000\end{array}$ & $\begin{array}{c}0.2 \\
1.000\end{array}$ & $\begin{array}{r}0.1 \\
1.000\end{array}$ & $\begin{array}{c}0.2 \\
1.000\end{array}$ & $\begin{array}{r}0.1 \\
1.000\end{array}$ & $\begin{array}{c}0.2 \\
1.000\end{array}$ & $\begin{array}{c}0.1 \\
1.000\end{array}$ & $\begin{array}{c}0.2 \\
1.000\end{array}$ \\
\hline 0 & .985 & .970 & .983 & .968 & .966 & .930 & .973 & .945 \\
\hline 1 & .969 & .939 & .975 & .956 & .940 & .878 & .950 & .899 \\
\hline 2 & .955 & .912 & .972 & .959 & .922 & .845 & .933 & .865 \\
\hline 3 & .943 & .889 & .974 & .973 & .911 & .830 & .921 & .842 \\
\hline 4 & .934 & .869 & .980 & .993 & .905 & .827 & .913 & .828 \\
\hline 5 & .926 & .854 & .986 & 1.015 & .904 & .832 & .908 & .822 \\
\hline 6 & .920 & .841 & .994 & 1.036 & .906 & .841 & .906 & .820 \\
\hline 7 & .915 & .832 & 1.002 & 1.056 & .909 & .852 & .906 & .822 \\
\hline 8 & .912 & .824 & 1.009 & 1.074 & .913 & .864 & .906 & .825 \\
\hline 9 & $.909 *$ & .819 & 1.016 & 1.090 & .918 & .874 & .908 & .829 \\
\hline 10 & .907 & .814 & 1.022 & 1.103 & .922 & .884 & .909 & .833 \\
\hline 15 & .902 & $.804 x$ & 1.044 & 1.143 & .940 & .914 & .919 & .852 \\
\hline 25 & .900 & .800 & $1.058 *$ & $1.162 *$ & $.952 *$ & $.930 *$ & $.927 *$ & $.864^{\star}$ \\
\hline$\infty$ & .900 & .800 & 1.061 & 1.164 & .955 & .932 & .929 & .867 \\
\hline
\end{tabular}

$\square$ - indicates a minimum or maximum

* - convergence to within $1 \%$ of new steady-state value. 